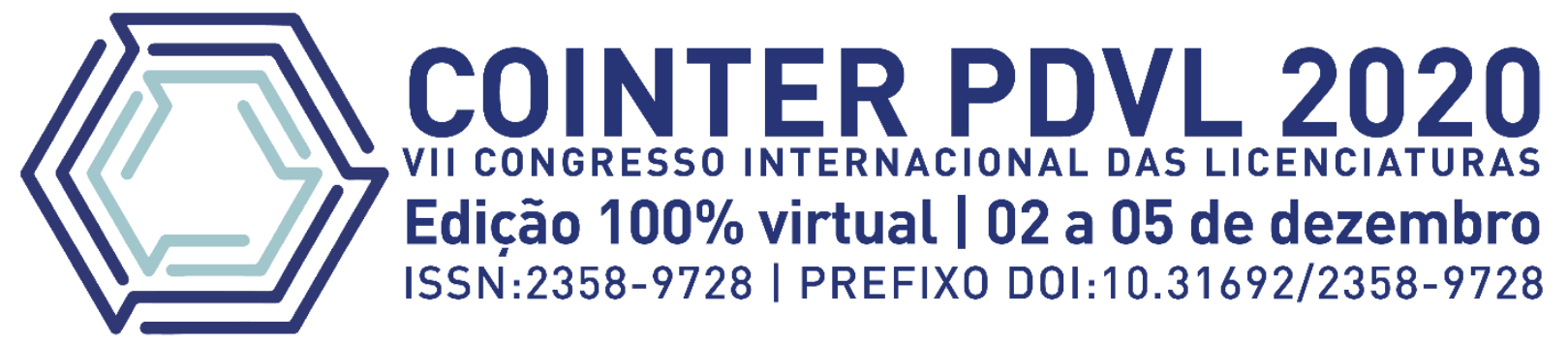

\title{
O USO METODOLÓGICO DAS OFICINAS COMO RECURSO IMINENTE: LIBRAS COMO L2 PARA OUVINTE
}

\section{EL USO METODOLÓGICO DE LOS TALLERES COMO RECURSO INMINENTE: LIBRAS COMO L2 PARA OYENTES}

\section{THE METHODOLOGICAL USE OF THE WORKSHOPS AS AN IMMINENT RESOURCE: LIBRAS LIKE L2 FOR LISTENERS}

\author{
Apresentação: Comunicação Oral \\ Jaqueline Costa da Silva Lima ${ }^{1}$; Lúcio Costa de Andrade ${ }^{2}$; José Roniero Diodato ${ }^{3}$; Nathalia da Costa Santos ${ }^{4}$; \\ Ayrton Matheus da Silva Nascimento ${ }^{5}$
}

DOI: https://doi.org/10.31692/2358-9728.VIICOINTERPDVL.0302

\begin{abstract}
RESUMO
Partindo do princípio que as oficinas de libras são exímios momentos de progresso das formas de integração com o outro e que favorecem as relações humanas na instituição escolar. O nosso trabalho foi pautado na procura de resultados questionando como o docente vem construindo com sua metodologia nas escolas através das oficinas de libras; bem como em compreender os benefícios trazidos para o ensino-aprendizado do aluno incluso. A busca por uma metodologia dentro de uma perspectiva inovadora nos levou, então, ao encontro de publicações da Revista Brasileira de Educação Especial, revelando-nos o quanto precisamos estar em constantes pesquisas e adaptações. Assim, o desenvolvimento desse estudo bibliográfico é de cunho qualitativo, nos debruçamos na revisão de artigos, livros, revistas e documentos, disponíveis na plataforma Scielo, os quais abordam o tema estudado e igualmente o contexto linguístico que envolve o processo de ensino e aprendizagem da libras pelo aluno ouvinte. No decurso dessa pesquisa 15 trabalhos foram encontrados na plataforma de pesquisa e destes utilizamos 3 devido às temáticas terem aproximação com a análise realizada. No qual utilizamos a análise documental de autores que discutem sobre o tema dentre eles destacam-se Felício (2019), Silva (2015), Baalbaki; Teixeira (2014) e Tondinelli (2016). Então, para dar conta dessa experiência pedagógica o educador em sua formação profissional deverá buscar meios de se capacitar para construir uma metodologia pautada nos direitos humanos, na inclusão, nos estudos culturais surdos, na cultura surda como um todo. Uma coisa é certa: vimos, com clareza solar, na pesquisa documental como é relevante o ensino de libras para ouvintes através de uma perspectiva inovadora, lúdica, de interação com a comunidade surda.
\end{abstract}

\footnotetext{
1 Pedagoga, Graduanda em Letras Libras, pelo Centro Universitário Leonardo Da Vinci/UNIASSELVI, Especialista em Psicopedagogia Clínica pela UNIFACOL e Proficiência em Tradução e Interpretação da Libras pela ALPHA, jaqueline.costal@ufpe.br

${ }^{2}$ Pedagogo, Graduando em Letras Libras, Universidade Federal da Paraíba/UFPB, lucio.costa@ academico.ufpb.br

${ }^{3}$ Pedagogo, Graduando em Letras Libras, Universidade Federal de Pernambuco/UFPE, roniero.diodato@ufpe.br

${ }^{4}$ Licenciada em Letras Libras, UFPE, Especialista em Libras e Educação Inclusiva da Pessoa Surda, pela ALPHA e Graduanda em Letras Português, pela Universidade Estácio de Sá, nathalia.costaa94@gmail.com

${ }^{5}$ Mestrando em Educação em Ciências e Matemática - PPGECM, pela Universidade Federal de Pernambuco (UFPE/CAA), Especialista em Ensino de Química e Graduado em Licenciatura em Química pelo Instituto Federal de Pernambuco (IFPE - Campus Vitória), ayrton.nascimento@ufpe.br
} 


\title{
O USO METODOLÓGICO DAS OFICINAS COMO RECURSO IMINENTE
}

\author{
Palavras-Chave: Metodologia, Oficinas, Libras, Ensino
}

\section{RESUMEN}

Asumiendo que los talleres de libra son excelentes momentos de avance en las formas de integración con el otro y que favorecen las relaciones humanas en la institución escolar. Nuestro trabajo se basó en la búsqueda de resultados, cuestionando cómo el docente ha ido construyendo con su metodología en las escuelas a través de talleres sobre libras; así como en la comprensión de los beneficios aportados a la enseñanza-aprendizaje del alumno incluido. La búsqueda de una metodología dentro de una perspectiva innovadora nos llevó, entonces, a encontrar publicaciones de la Revista Brasileira de Educação Especial, que nos revelaron cuánto necesitamos estar en constante investigación y adaptaciones. Así, el desarrollo de este estudio bibliográfico es de carácter cualitativo, nos centramos en la revisión de artículos, libros, revistas y documentos, disponibles en la plataforma Scielo, que abordan el tema estudiado y también el contexto lingüístico que involucra el proceso de enseñanza y aprendizaje de libras por el estudiante que escucha. En el transcurso de esta investigación se encontraron 15 trabajos en la plataforma de investigación y de estos, se utilizaron 3 porque los temas se acercaron al análisis realizado. En el cual utilizamos el análisis documental de autores que discuten el tema, entre ellos se encuentran Felício (2019), Silva (2015), Baalbaki; Teixeira (2014) y Tondinelli (2016). Entonces, para hacer frente a esta experiencia pedagógica, el educador en su formación profesional debe buscar formas de capacitarse para construir una metodología basada en los derechos humanos, la inclusión, los estudios culturales sordos, la cultura sorda en su conjunto. Una cosa es cierta: vimos, con claridad solar, en la investigación documental lo relevante que es la enseñanza de libras a los oyentes a través de una perspectiva innovadora, lúdica, de interacción con la comunidad sorda.

Palabras Clave: Metodología, Talleres, Libras, Docencia

\section{ABSTRACT}

Assuming that the pound workshops are excellent moments of progress in the forms of integration with the other and that they favor human relations in the school institution. Our work based was on the search for results, questioning how the teacher has been building with his methodology in schools through workshops on pounds; as well as in understanding the benefits brought to the learning teaching- of the included student. The search for a methodology within an innovative perspective led us, then, to find publications from the Brazilian Journal of Special Education, revealing to us how much we need to be in constant research and adaptations. Thus, the development of this bibliographic study is of a qualitative nature, we focus on the review of articles, books, magazines and documents, available on the Scielo platform, which address the topic studied also and the linguistic context that involves the teaching and learning process of pounds by the listening student. In the course of this research, 15 works found were on the research platform and of these; we used three because the themes were close to the analysis performed. In which we use the documentary analysis of authors who discuss the theme, among them are Felício (2019), Silva (2015), Baalbaki; Teixeira (2014) and Tondinelli (2016). Therefore, in order to cope with this pedagogical experience, the educator in his professional training should look for ways to train himself to build a methodology based on human rights, inclusion, deaf cultural studies, and deaf culture as a whole. One thing is certain: we saw, with solar clarity, in documentary research how relevant the teaching of pounds to listeners is through an innovative, playful perspective, of interaction with the deaf community.

Keywords: Methodology, Workshops, Libras, Teaching

\section{INTRODUÇÃO}

Cada vez mais a acessibilidade tem ganhado força na sociedade, uma vez que as pessoas com deficiência têm buscado assumir seu papel enquanto cidadãos participantes. De igual modo ocorre no contexto educacional, no qual o Governo Federal tem adotado medidas de inclusão de alunos com deficiências nas escolas de ensino regular. Porém, o que geralmente acontece é um despreparo por parte das escolas para acolher esses alunos de forma satisfatória. 
No cotidiano escolar, a educação inclusiva tem exigido por parte dos educadores um planejamento mais amplo das estratégias de ensino, com o desenvolvimento de ferramentas que possibilitem auxiliar os estudantes especiais, de acordo com suas necessidades. Com os estudantes surdos não poderia ser diferente. Embora tenham a Libras como principal meio de comunicação, percebe-se a necessidade de dinamizar as ferramentas e metodologias para ampliar ainda mais o aprendizado do estudante surdo e sua interação com os ouvintes.

Diante deste cenário, a pergunta que fazemos é: "como o uso de oficinas podem auxiliar o ensino da Libras para alunos ouvintes?" Perante o contexto apresentado, objetivamos despertar o interesse dos alunos ouvintes pela Língua Brasileira de Sinais, facilitar o ensino da Libras através de atividades lúdicas e conscientizar os alunos ouvintes sobre a importância de aprender a Libras como L2.

Com base em pesquisas bibliográficas realizadas em autores como Felício (2019), Silva (2015), Baalbaki; Teixeira (2014) e Tondinelli (2016) entre outros, é possível afirmar que o processo de inclusão escolar dos alunos surdos ainda possui muitas lacunas, principalmente no tocante aos entraves linguísticos que permeiam as relações cotidianas. No entanto a criação de mecanismos que proporcionem o ensino da Libras para os alunos ouvintes, auxiliam de forma muito satisfatória essa interação entre surdos e ouvintes, promovendo a equidade entre os discentes e favorecendo o desenvolvimento escolar.

Visando minimizar o déficit educacional, é de extrema importância que alunos surdos e ouvintes, enquanto estudantes do espaço escolar, possam se comunicar de forma efetiva através da Libras, e é papel da escola proporcionar meios de ensino dessa Língua como L2 para os alunos ouvintes. A utilização criativa dos mais diversos mecanismos de ensino existentes para a inclusão dos surdos no cotidiano escolar requer um maior esforço por parte dos professores e demais profissionais da educação para melhorar a comunicação com o estudante surdo de sua escola, através de práticas metodológicas que estreite sua interação.

À vista disso, o presente trabalho propõe a organização de oficinas direcionadas ao ensino da Libras como uma das metodologias sugeridas e como ocorre a construção do saber metodológico nas escolas por meio das oficinas de Libras direcionadas tanto aos professores da instituição que o estudante surdo está inserido, quanto os outros profissionais da educação que trabalham na escola, sejam eles ouvintes ou não. Os objetivos estão pautados nos benefícios que as oficinas de Libras oferecem à comunidade e, em especial aos alunos surdos; pois quando a comunidade aprende a Libras e a utiliza no cotidiano escolar a cultura surda é fortalecida despertando um sentimento de pertencimento por esses.

Por certo, o contato direto com o conteúdo da Língua de Sinais Brasileira através dos 


\section{O USO METODOLÓGICO DAS OFICINAS COMO RECURSO IMINENTE}

profissionais responsáveis para essa ação irá constituir num dos principais eixos formativos das oficinas, tendo o diálogo como elemento caracterizador das atividades pedagógicas. Assim sendo, a proposta inclusiva está predominante direcionada a melhoria das respostas educativas que se oferecem a quaisquer alunos independentemente de suas condições, pessoais, sociais ou culturais. Além da proposta inclusiva, facilitar a aprendizagem dos alunos inclusos fará com que esses indivíduos tenham mais autonomia dentro do âmbito escolar, garantindo à possibilidade desenvolvimento dentro da perspectiva inovadora que promove a habilidade de se comunicar em Libras através de uma metodologia pautada numa dinâmica de ação e reflexão.

\section{FUNDAMENTAÇÃO TEÓRICA}

$\mathrm{Na}$ atualidade, a educação inclusiva tem exigido um planejamento muito mais amplo no tocante a elaboração de metodologias de ensino, de modo a atender as demandas especiais apresentadas pelos alunos surdos. Em outros termos, faz-se necessário no cotidiano escolar, o desenvolvimento de ferramentas que consigam, de forma mais consistente e eficaz, auxiliar no processo de ensino-aprendizagem desse nicho educacional, atendendo com isso, as necessidades por eles apresentadas (FELICIO, et al., 2019).

Destaca-se então que diante deste cenário, a inclusão dos discentes não ouvintes no dia a dia das escolas tem sido desenvolvida de diferentes formas, porém, tendo a Libras como peça central e porta de entrada de todo o processo. Requerendo com isso, uma apresentação e introdução ao público de maneira interativa, que objetiva à propagação da importância da integração e o despertar do interesse dos alunos frente a referida língua (SILVA, et al., 2015).

A área educacional possui uma série de metodologias e ferramentas voltadas a maximização do aprendizado, dentre as quais destaca-se aqui as oficinas, que de forma geral, visão articular a teoria à prática, construindo conhecimento através das ações realizadas. Ou seja, elas contribuem para a construção de uma discussão sobre aspectos teóricos e práticos acerca de um referido conteúdo ou assunto, podendo ser caracterizadas como uma composição coletiva de um saber, no qual constitui-se não apenas pelo resultado final, mas também por todo o seu processo de ensino (BAALBAKI; TEIXEIRA, 2014).

No contexto da surdez, seu desenvolvimento traz como um de seus objetivos centrais a promoção do saber, seja ele direcionado a alfabetização, a difusão científica, o ensino das diferentes comunicações e etc. Além disso, elas também contribuem na interação do público escolar, levando a uma reflexão sobre a diversidade do cenário linguístico e a inclusão dos alunos surdos na escola (RIBEIRO; SHOLL-FRANCO, 2018).

As oficinas quando direcionadas ao ensino da Libras podem ser executadas tanto pelos 
professores da própria instituição educacional, quanto por outros profissionais, sejam eles surdos ou não, porém, considera-se pertinente expor, que o desenvolvimento por parte de um profissional também surdo, pode enriquecer ainda mais a prática, isso porque os alunos passam a ter a oportunidade de vivenciar o sucesso de alguém que apresenta as mesmas características que a sua (OLIVEIRA, 2017).

Essa vivência faz parte da interação participativa ofertada pela oficina, ou seja, o contato direto com o conteúdo e com o profissional responsável pelo desenvolvimento é um dos eixos formativos, tendo o diálogo como elemento caracterizador de suas atividades pedagógicas. Essa interação dialógica entre o público e o mediador promove maior aquisição de conhecimento, além de ofertar aos alunos surdos uma aproximação maior e também extracurricular com a língua de sinais, através de uma série de ferramentas, como por exemplo, exposição de ideias e jogos (RIBEIRO; SHOLL-FRANCO, 2018).

Além das ferramentas acima citadas, os responsáveis pela execução de oficinas também podem contar com diversas tecnologias disponíveis na atualidade, em outras palavras, com o advento tecnológico, o fazer pedagógico passou a dispor de novos meios de transmissão de conhecimento, uma vez que "com um toque, informações podem ser acessadas em velocidades cada vez maiores" (FELICIO, et al., 2019, p. 206), facilitando com isso o ensino e o aprendizado, além de contribuir para tornar o processo muito mais inclusivo e atrativo (BAALBAKI; TEIXEIRA, 2014).

Neste cenário tecnológico destaca-se que, segundo explicitado por Felício, et al., (2019, p. 204):

\footnotetext{
O smartphone é uma das diversas tecnologias presentes na sociedade atual que podem ser utilizadas como ferramenta educacional para pessoas com necessidades especiais, isso deve-se pelo fato de ser acessível e repleto de funcionalidades que podem ser utilizadas no âmbito escolar.
}

Como pode ser observado na citação acima transcrita, dentre os vários aparatos tecnológicos existentes na atualidade, o celular e os aplicativos que o compõe ganham um destaque especial, isso porque, uma das ferramentas mais próximas e acessíveis aos alunos, podem ser amplamente utilizados durante a execução de uma oficina de Libras, de modo a facilitar a compreensão do conteúdo transmitido (TONDINELLI, 2016).

A oficina no contexto educacional possui uma função experimental no que se refere a essa língua, ou seja, ao mesmo tempo em que atua no ensinamento dos sinais, desempenha um papel relevante na inclusão dos ouvintes no cotidiano das pessoas surdas. Isto é, com atividades direcionadas que simulam a surdez, como por exemplo, assistir a uma TV sem o som, as oficinas 


\section{O USO METODOLÓGICO DAS OFICINAS COMO RECURSO IMINENTE}

conseguem propiciar aos participantes uma vivencia mais próxima da realidade do surdos, levando-os a uma reflexão maior acerca da importância do ensino da Língua Brasileira de Sinais no espaço escolar (BAALBAK, et al., 2016).

Observa-se então, que a referida ferramenta educacional possui um vasto conjunto de elementos, que aplicados de forma direcionada, consegue agregar conhecimentos e experiências em todo o seu processo de execução. Nela, o profissional conta com muitos recursos, como vídeos, jogos lúdicos, materiais didáticos, que são utilizados de modo a ensinar a Libras através de músicas, produções teatrais, diálogos e etc., conduzindo os alunos, surdos ou não, a um aprendizado prazeroso, além de facilitar o trabalho do educador/mediador (SILVA, et al., 2015).

A eficácia pedagógica de uma oficina, também encontra-se na diversidade de conteúdos que podem ser abordados com sua utilização, ou seja, a mesma consegue explanar diversos assuntos, interligando-os com o aprendizado dos sinais, como é o caso da proposta idealizada por Cardoso Junior (2018), que unificou em seu projeto o ensino da escrita da língua portuguesa como segunda língua, através da produção de cartazes e redações com a temática da corrupção, agrupando isso com o aprofundamento do conhecimento da Libras.

Com isso, contribui para reunir profissionais, que por meio de suas experiências educacionais, promovam um debate acerca das questões ligadas ao aprendizado por parte dos alunos surdos, da língua de sinais como L1 e a língua portuguesa como L2, assim como para o planejamento e desenvolvimento de materiais adaptados que auxiliam o professor durante suas aulas, e que tornam o ensino mais inclusivo, integrando esses discentes ao cotidiano escolar (BAALBAKI; TEIXEIRA, 2014).

É importante destacar, que a oficina como metodologia de ensino da Língua Brasileira de Sinais, desempenha papel primordial na identificação das percepções sobre a surdez e sobre conhecimento da diversidade por parte dos discentes. Além disso, é possível o levantamento acerca das dificuldades e limitações que são enfrentadas nessa realidade possibilitando uma coleta de informações relevantes que serviram de base para o planejamento e escolha dos meios que serão utilizados de modo a sanar os obstáculos encontrados, potencializando o processo de ensino-aprendizado (TONDINELLI, 2016).

Tudo isso conduz ao entendimento de que as:

Oficinas de Libras, tem a proposta de ensinar aos alunos a Língua Brasileira de Sinais, permitindo com que tenham um contato à língua, gerando possibilidades de progressos e consolidação dessa linguagem. Assim como, o entendimento dos direitos das pessoas surdas, para o fim da discriminação na sociedade. Afinal, a Língua de Sinais deve ser respeitada como qualquer outra, pois, tem a mesma função da língua 
oral: a comunicação (SILVA; FREITAS, 2018, p. 1).

Com base no exposto, torna-se possível afirmar que a inclusão dos surdos no cotidiano escolar requer dos professores e demais profissionais da área educacional, a utilização criativa dos mais diversos mecanismo de ensino existentes, e neste contexto as oficinas surgem trazendo consigo um conjunto de métodos, que postos em práticas permitem ao aluno apropriarem-se da Libras, de modo a adquirirem o conhecimento da mesma e através dela, alcançarem os demais saberes demandados pela atual sociedade letrada (CARDOSO JUNIOR, 2018).

Dentro das oficinas de libras, a ação da construção do saber é construída através da vivência concreta. Cuberes apud Vieira e Volquind (2002, p.11), conceitua a oficina como sendo:

Um tempo e um espaço para aprendizagem, um processo ativo de transformação recíproca entre sujeito e objeto, um caminho com alternativas, com equilíbrio que nos aproximam progressivamente do objeto a conhecer.

A vivência das oficinas de libras dentro das instituições escolares traz benefícios que abrangem todo um leque tanto de ação quanto de reflexão integral dos alunos. Isso se dá porque para que bons resultados educacionais sejam alcançados no que se refere ao aluno surdo, suas condições linguísticas e culturais devem ser essencialmente consideradas no processo de aprendizagem (SACKS, 2002). Como fica notório nos dados apresentados por Silva (2015) a relevância da oficinas na promoção tanto da compreensão da Libras como da Língua Portuguesa.

Figura 01: Idade de aquisição da língua de sinais e o percentual de acerto nos testes de compreensão leitora.

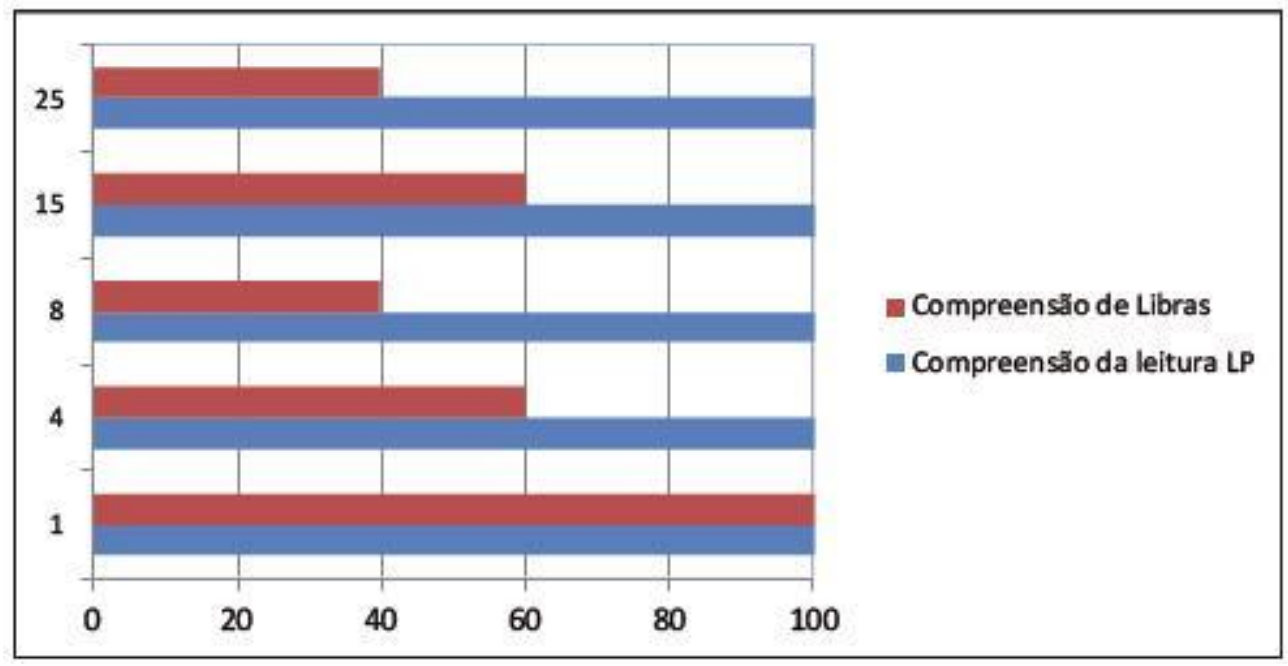

Fonte: Silva (2015) 


\section{O USO METODOLÓGICO DAS OFICINAS COMO RECURSO IMINENTE}

Assim, fica claro que a utilização das oficinas de Libras para a compreensão da língua de sinais são exímios recursos para o progresso das formas de integração com o outro, bem como para o fortalecimento das relações humanas na instituição escolar. Sobre este tema, Hora (2002, p. 59) pontua que para que haja o engajamento da comunidade escolar deve ser reconhecida a língua em uso dos sujeitos, nesse caso dos surdos a língua de sinais.

Dessa maneira, à necessidade de promover a articulação entre a escola e a comunidade a que se serve é fundamental. O entendimento de que a escola não é um órgão isolado do contexto global de que faz parte, deve estar presente no processo de organização de modo que as ações a serem desenvolvidos estejam voltadas para as necessidades comunitárias.

O crescimento individual e coletivo coopera, assim, para o avanço de todos. E, ainda, se tem estímulo e se desenvolve a empatia; dois pilares que trazem muitos benefícios na vida de quem almeja crescimento educacional. Potencialidades, comunicação e a condição para o crescimento da consciência inclusiva e a maior interatividade com a turma também fazem parte desse processo.

A comunidade escolar, no entanto, ao se empenhar com a oferta de oficinas em libras precisa pensar de forma ampla e envolver realmente todos. Os surdos e os ouvintes numa perspectiva inovadora, quando tem oportunidade de participar de tais oficinas, interagem melhor, vivenciam o lúdico e a afetividade.

Para dar conta dessa experiência pedagógica, no entanto, o educador em sua formação profissional deverá buscar meios de se capacitar para construir junto com a família uma metodologia pautada nos direitos humanos, na inclusão, nos estudos culturais surdos, na cultura surda como um todo.

\section{A importância da aquisição da Libras como L2 por meio de recursos metodológicos} das oficinas de libras.

O ato de incluir é para todo mundo, cabendo às escolas adaptações necessárias de acordo com suas especificidades. As oficinas de libras geram um ambiente propício para incluir socialmente sem descriminação. Com este trabalho de acessibilidade comunicacional, escola assume nova identidade, passa a não ser mais a mesma diante dos obstáculos dos protagonistas, frente a situações típicas de exclusão do aluno.

O professor, por sua vez, precisa se dedicar a conhecer os estudantes inclusos, os quais poderão contribuir muito nas oficinas de libras. Com isto, a tomada de decisão, numa visão 
reflexiva, deve favorecer todos os envolvidos. Assim, o professor passa a ser intensamente um agente de transformação da escola, ao ofertar um ensino sem desigualdades, com acessibilidade atitudinal e comunicacional.

Para Gomes (2002, p. 71) “[...] esse potencial precisa ser descoberto, desenvolvido, provocado e levado a sério pelo sistema educacional". Usar uma metodologia ampla com diferentes estratégias requer do profissional que estar à frente das oficinas de libras um empenho maior.

Segundo Silva (2012, p. 5):

As atividades elaboradas durante a oficina recebem o total apoio e motivação para que haja colaboração e participação de todos. A intenção também é formar profissionais conscientes e aliar alegria, dinâmicas, prazer e brincadeiras que tragam ideias de que aprender seja algo essencialmente prazeroso e coletivo.

A intenção realmente é a de construir um ambiente inovador, o qual não esteja focado apenas em sinais, mas em cultura. Os discentes agregam teoria e pratica aquilo que é vivenciado dentro das oficinas de libras. Oportunizar conhecimentos concretos é qualificar o aluno incluso numa perspectiva ousada do saber metodológico.

Nesse contexto, Glat (1991) afirma que a integração "é um processo espontâneo e subjetivo, que envolve direta e pessoalmente o relacionamento entre seres humanos". Rodrigues (2006) complementa ao relatar que “a integração pressupõe uma 'participação tutelada', uma estrutura com valores próprios aos alunos 'integrados 'que têm que se adaptar". Os autores opinam que na realidade a inclusão não aconteceu. É imprescindível que o professor inove suas aulas rompendo esse modelo de integração engessada.

\section{METODOLOGIA}

Para o desenvolvimento desse estudo bibliográfico e de cunho qualitativo, nos debruçamos na revisão de artigos, livros, revistas e documentos, disponíveis na plataforma Scielo, os quais abordam o tema estudado e igualmente o contexto linguístico que envolve o processo de ensino e aprendizagem da Libras pelo aluno ouvinte que apresentamos no texto como L2.

Assim, para descrever melhor os achados, no Scielo com o descritor "oficina de libras" apareceu apenas um trabalho, o qual não foi contemplado aqui por ter como foco o ensino superior. Com o descritor "ensino de libras para ouvintes" apareceram 15 trabalhos. Destes apenas três se referem ao ensino de Libras e compõem o nosso corpus de análise. Assim, 


\section{O USO METODOLÓGICO DAS OFICINAS COMO RECURSO IMINENTE}

seguimos numa perspectiva mais global, transdisciplinar na construção do presente.

Dentro dessa proposta, recorremos a pesquisas em revistas científicas que abordam o tema estudado, enriquecendo assim os dados para análise da situação problema, utilizando como base estudos publicados por Felício, Silva, Baalbaki; Teixeira e Tondinelli, além dos decretos e leis que asseguram a educação dos surdos no Brasil, uma vez que "as pesquisas que se valem de dados existentes permitem resultados mais acurados nas pesquisas referentes" (GIL, 2008, p. 154).

Aqui vale ressaltar que a importância de um estudo deste tipo pode sinalizar mudanças de conceitos e papéis dentro do contexto educacional. No decurso dessa pesquisa 15 trabalhos foram encontrados na plataforma de pesquisa e destes utilizamos 3 devido às temáticas terem aproximação com a análise realizada.

\section{RESULTADOS E DISCUSSÃO}

O nosso trabalho foi pautado numa procura de resultados questionando como o docente vem construindo sua metodologia nas escolas através das oficinas de libras; bem como em compreender os benefícios trazidos para o ensino-aprendizado do aluno incluso. A busca por uma metodologia dentro de uma perspectiva inovadora nos levou, então, ao encontro de publicações da Revista Brasileira de Educação Especial, revelando-nos o quanto precisamos estar em constantes pesquisas e adaptações.

As autoras Belvillacqua e Formigoni (2003) e Corrêa (1999) apontam que a inclusão tem sido vista como algo que propiciará aos indivíduos surdos melhores condições de desenvolvimento por possibilitar o estabelecimento de relações mais próximas com as crianças ouvintes dentro da escola, podendo o surdo dessa forma adaptar-se melhor à sociedade ouvinte (ASPILICUETA, et al., 2013).

A revista Lusófona de Educação cita, Dorziat (2004a) e Tenor (2008) em que o aluno surdo inserido em classe comum irá encontrar um contexto escolar que não respeita sua singularidade, a utilização da língua de sinais. Com isso fica claro que adaptar o meio faz necessário para o bem estar de todos os envolvidos. A comunidade escolar precisa priorizar uma convivência harmoniosa entre os pares e tudo se encaixara conforme as adaptações. Neste sentido, as oficinas de libras são importantíssimas.

Direcionamos a proposta dessa pesquisa, fazendo o levantamento teórico e metodológico referente a oficinas como metodologia de ensino de libras para surdos como L1 e para ouvintes como L2. Com base nessa perspectiva é possível analisar a necessidade de estudantes surdos e ouvintes quanto o uso e fluência em libras, através das tarefas realizadas 
durante o decorrer das oficinas como: explanação da cultura surda com suas mudanças e atualização, o emprego do vocabulário em libras, tendo como avaliação realização de exercícios teóricos e práticos.

As oficinas quando direcionadas ao ensino da Libras podem ser executadas tanto pelos professores da própria instituição educacional, quanto por outros profissionais, sejam eles surdos ou não, porém, considera-se pertinente expor, que o desenvolvimento por parte de um profissional também surdo, pode enriquecer ainda mais a prática, isso porque os alunos passam a ter a oportunidade de vivenciar o sucesso de alguém que apresenta as mesmas características que a sua (OLIVEIRA, 2017).

Diante do exposto compreende que aulas de libras no ensino regular é uma coisa nova que está aberta a mudanças que muitas vezes nos leva a encontrar obstáculos por falta de conhecimento da libras por uma grande maioria dos profissionais do ensino regular, mais acreditamos que são esses os primeiros passos a serem traçados para dá ênfase a uma educação inclusiva. Sabemos que, com as oficinas de libras a aprendizagem torna-se mais fácil e os alunos aprendem brincando com os jogos utilizados, assim tornando uma aula mais prazerosa de forma lúdica.

Por fim, temos o relato de uma experiência onde foi ofertada a oficina de Língua Brasileira de Sinais (LIBRAS), na qual expõem que a escola precisa estar apta a estimular os seus alunos, sendo um diferencial e não apenas um repetidor da sociedade, formando cidadãos conscientes, que respeitem e que percebam o outro como um ser igual em direitos e valores.

E, nesse sentido, esse terceiro trabalho reitera que ofertar oficinas como metodologia de ensino de libras nos âmbitos escolares abre caminhos para o novo, para a inclusão, para o fortalecimento da identidade, cultura e língua da comunidade surda. A prática narrativa da pelos autores mostram como os envolvidos participaram nas adaptações necessárias e demonstraram um aprendizado respeitoso com seus pares; isso fortalece a nossa esperança por uma educação bilíngue, sem barreiras linguísticas, atitudinais e culturais.

No geral, a falta de material pedagógico adequado para atuar em sala de aula é um entrave no processo de ensino-aprendizagem nas escolas, e quando se trata do ensino da Língua Brasileira de Sinais, o desafio é ainda maior. Por isso, é tão importante buscar por métodos alternativos que auxiliem na aprendizagem da Libras em sala de aula (SILVA e SANTOS, 2019).

Desse modo, as atividades lúdicas para o ensino de uma nova língua permite que o aluno use a imaginação como principal ferramenta para adquirir novos conhecimentos, estimulando sua criatividade e seus interesses perante o que está sendo proposto. E assim, diminuindo o 


\section{O USO METODOLÓGICO DAS OFICINAS COMO RECURSO IMINENTE}

distanciamento que existe entre a proposta de inclusão e o que realmente é praticado em sala de aula, é possível fazer adaptações com jogos para a inserção da Libras no contexto educacional (SILVA E SANTOS, 2019).

Em outras palavras, o uso das práticas pedagógicas como ações facilitadoras no cotidiano escolar proporciona um aprendizado prazeroso, dinâmico e criativo, além de estimular a absorção do conhecimento principalmente da Libras que é de uma modalidade comunicativa visual-gestual diferente do português que é oral-auditiva.

\section{CONCLUSÕES}

Tendo em vista os aspectos observados e mencionados pelos autores pesquisados neste trabalho, concluímos que as adaptações da rotina escolar, as intervenções são necessárias para oportunizar formação integral e inclusiva. A inclusão faz parte de um processo no qual é inadmissível a manutenção de qualquer tipo de barreira. E, na seara da educação, a pesquisa continua é uma necessidade do profissional que quer fazer a diferença, principalmente quando lida com cultura surda e cultura ouvinte nos mesmos espaços e tempos pedagógicos.

Em vista disso, a introdução do ensino da Língua Brasileira de Sinais como ferramenta de promoção da inclusão no ambiente escolar traz consigo muitas contribuições para o aprendizado dos estudantes ouvintes. Através das oficinas, estes estudantes podem conhecer a Libras e praticar a sua comunicação, adquirindo-a como segunda língua L2, ampliando assim o seu sistema de comunicação. Conscientes, esses estudantes seriam replicadores dessa aprendizagem, difundindo esse ensino dentro e fora da escola, favorecendo para o aumento no número de pessoas que fazem uso da língua de sinais.

Dessa maneira, as oficinas de Libras, assim como já detalhado no desenvolver desta pesquisa, são instrumentos de inclusão social, pois a empatia, respeito e interação são os valores que agregam a essa metodologia, eficácia no feedback esperado. O ensino dos sinais, o alfabeto manual, números etc., são apresentados de maneira dinâmica, com momentos ministrados por profissionais qualificados e experientes para que seja estabelecida uma troca prazerosa, os conhecimentos entre os docentes e estudantes.

Em suma, a inclusão do estudante surdo no ambiente educacional requer de todos os profissionais envolvidos no processo educativo a utilização de mecanismos diversificados e criativos para sua aprendizagem, destacando-se a oficina de Libras como uma das ferramentas encontrada para ajudar nesse processo, demonstrando quais os principais benefícios desta metodologia no cotidiano educacional do estudante surdo.

Por fim, podemos afirmar que o itinerário aqui registrado nos auxiliou a desenvolver 
competências de investigação, seleção, organização e comunicação da informação e, ainda, nos trouxe sugestão para estudos futuros a serem aprofundados. Uma coisa é certa: vimos, com clareza, na pesquisa documental como é relevante o ensino de Libras para ouvintes através de uma perspectiva inovadora, lúdica, de interação com a comunidade surda.

\section{REFERÊNCIAS}

ASPILICUETA, Patricia et al . A questão linguística na inclusão escolar de alunos surdos: ambiente regular inclusivo versus ambiente exclusivamente ouvinte. Rev. bras. educ. espec., Marília , v. 19, n. 3, p. 395-410, set. 2013 . Disponível em $<$ http://www.scielo.br/scielo.php?script=sci_arttext\&pid=S1413$65382013000300007 \& \operatorname{lng}=$ pt\&nrm=iso $>$. acessos em 15 out. 2020.

BAALBAKI, A. C. F. et al. Oficinas para professores: português Como segunda língua para alunos surdos. Rev. Ciênc. Ext. v. 12, n. 1, p. 129-145, 2016. Disponível em: $<$ https://ojs.unesp.br/index.php/revista_proex/article/view/1096/1181>. Acesso em 30 jan. 2020.

BAALBAKI, A. C. F; TEIXEIRA, V. G. Lugar de transformações: a oficina como prática pedagógica no ensino de português para surdos. Revista Práticas de Linguagem. v. 4, n. 2 , jul./dez. 2014. Disponível em: <http://www.ufjf.br/praticasdelinguagem/files/2014/09/89-96Lugar-de-transforma\%C3\%A7\%C3\%B5es-a-oficina-como-pr\%C3\%A1ticapedag\%C3\%B3gica-no-ensino-de-portugu\%C3\%AAs-para-surdos.pdf $>$. Acesso em 30 jan. 2020.

BEVILACQUA, M. C; FORMIGONI P. G. M. Audiologia educacional: uma opção terapêutica para a criança deficiente auditiva. 3. ed. São Paulo: Pró Fono, 2003.

CARDOSO JUNIOR, W. S. Oficina pedagógica de escrita para surdos usuários da Libras. PUC-SP. 2018.2 Disponível em: $<$ https://tede.pucsp.br/bitstream/handle/21137/2/Waldemar\%20dos\%20Santos\%20CardosoJunior.pdf>. Acesso em 01 fev. 2020.

CORRÊA, J. M. Surdez e os fatores que compõe o método audiovisual de linguagem oral para crianças com perda auditiva. São Paulo: Atheneu, 1999.

DORZIAT, A. Educação e surdez: o papel do ensino na visão de professores. Educar em Revista. V 23, Curitiba, Editora UFPB, 2004.

FELICIO, J. G. et al. As contribuições de uma oficina para a divulgação de aplicativos voltados para a comunicação de pessoas com necessidades auditivas e visuais no ensino médio. XVI Semana de Licenciatura. Revista IFG. 2019. Disponível em: <http://revistas.ifg.edu.br/semlic/article/view/694/469>. Acesso em 30 jan. 2020.

GLAT, Rosana. A integração social dos portadores de deficiência: uma reflexão. Rio de Janeiro: Sette Letras, 1991.

GOMES, Cristiano Mauro Assis. Feuerstein e a construção mediada do conhecimento. Porto Alegre: Artmed, 2002. 
GIL, Antônio Carlos. Métodos e Técnicas de Pesquisa Social. $6^{\text {a }}$ edição - São Paulo: Atlas S.A, 2008.

HORA, Dinar. Gestão democrática na escola: Artes e ofícios da participação coletiva. 9 ed. Campinas, SP: Papirus, 2002.

OLIVEIRA, C. B. P. O processo de ensino/aprendizagem a inclusão do aluno surdo no ensino regular de uma escola pública municipal de Floriano-PI. 2017. Disponível em: $<$ https://monografias.brasilescola.uol.com.br/pedagogia/o-processo-ensino-aprendizageminclusao-aluno-surdo-no-ensino-regular.htm>. Acesso em 30 jan. 2020.

RODRIGUES, David (org.). Educação Inclusiva: as boas e as más notícias. Perspectivas sobre a inclusão; da educação à sociedade. Porto: Porto, 2006.

RIBEIRO, N. S; SHOLL-FRANCO, A. Desafios educacionais em contextos multilíngues de ensino: uma proposta curricular inclusiva com línguas de sinais e neurociências. Periódico UDESC. 2018.2 Disponível em: <http://www.periodicos.udesc.br/index.php/colbeduca/article/view/11460/8247>. Acesso em 30 jan. 2020.

SACKS, O. Vendo vozes. Uma Viagem ao Mundo dos Surdos. São Paulo: Cia das Letras, 2002.

SILVA, Edjane Vasconcelos da. SANTOS, José de Queiroz Alves. Jogos com materiais recicláveis no ensino e aprendizagem da língua brasileira de sinais - Libras: relato de experiência. 2019. 42 f. Trabalho de Conclusão de Curso (Licenciatura Plena em Pedagogia) Centro de Educação, Núcleo de Educação a Distância/NEAD, Curso de Pedagogia - Polo Maceió, Universidade Federal de Alagoas, Maceió, 2019. Disponível em: http://www.repositorio.ufal.br/handle/riufal/6358. Acesso em 01 de março de 2020.

SILVA, João Da Mata Alves Da. O lúdico como metodologia para o ensino de crianças com deficiência intelectual. 2012 Disponível em: http://repositorio.roca.utfpr.edu.br/jspui/bitstream/1/4736/1/MD_EDUMTE_II_2012_33.pdf acesso em 26 março 2020.

SILVA, J. B; FREITAS, L. J. Relato de experiência: oficinas de libras para alunos do fundamental II de uma escola municipal de Nazaré da Mata - PE. III CINTEDI. 2018. Disponível em: <http://www.editorarealize.com.br/revistas/cintedi/trabalhos/TRABALHO_EV110_MD4_SA 13_ID1679_11072018102909.pdf>. Acesso em 01 fev. 2020.

SILVA, Simone Gonçalves de Lima da. Consequências da Aquisição Tardia da Língua Brasileira de Sinais na Compreensão Leitora da Língua Portuguesa, como Segunda Língua, em Sujeitos Surdos. Rev. bras. educ. espec., Marília , v. 21, n. 2, p. 275-288, jun. 2015 . Disponível em <http://www.scielo.br/scielo.php?script=sci_arttext\&pid=S141365382015000200275\&lng=pt\&nrm=iso>. acessos em 15 out. 2020.

SILVA, V. C. et al. Uma reflexão sobre o papel da Língua Brasileira de Sinais (LIBRAS) a partir de uma oficina nas turmas de $4^{\circ}$ ano do Centro Educacional Municipal Padre Januário Campos na cidade de Iguatu/CE. Revista CONEDU. 2015. Disponível em: 
<http://editorarealize.com.br/revistas/conedu/trabalhos/TRABALHO_EV073_MD1_SA11_I D2351_08092017115300.pdf>. Acesso em 01 fev. 2020.

TENOR, A.C. A inclusão do aluno surdo no ensino regular na perspectiva de professores da rede municipal de ensino de Botucatu.2008. Dissertação de Mestrado em Fonoaudiologia. Pontifícia Universidade Católica de São Paulo, SP, 2008.

TONDINELLI, M. O. Noções básicas de Libras para alunos ouvintes. Cadernos PDE Paraná. 2016. Disponível em: <http://www.diaadiaeducacao.pr.gov.br/portals/cadernospde/pdebusca/producoes_pde/2016/2 016_pdp_edespecial_uenp_mariaozanatondinelli.pdf>. Acesso em 03 fev. 2020.

VIEIRA, Elaine; VOLQUIND, Lea. Oficinas de ensino: O quê? Como? 4. Ed. Porto Alegre: Edipucrs, 2002. 